\title{
Análise Filogenética de Potyvírus Causando Endurecimento dos Frutos do Maracujazeiro no Nordeste do Brasil*
}

\author{
Ana Verônica S. Nascimento, ${ }^{1,2 * *}$, Ana R. R. Souza ${ }^{1}$, Poliane F. Alfenas ${ }^{1}$, Genira P. Andrade ${ }^{2}$, Murilo G. \\ Carvalho' $^{1}$, Gilvan Pio-Ribeiro ${ }^{2} \&$ F. Murilo Zerbini ${ }^{1 \#}$
}

'Departamento de Fitopatologia/BIOAGRO, Universidade Federal de Viçosa, Viçosa, MG, CEP 36570-000, e-mail: zerbini@ufv.br; ${ }^{2}$ Departamento de Agronomia, Laboratório de Fitovirologia, Universidade Federal Rural de Pernambuco, Recife, PE, CEP 52171-900

(Aceito para publicação em 25/05/2004)

Autor para correspondência: F. Murilo Zerbini

NASCIMENTO, A.V.S., SOUZA, A.R.R., ALFENAS, P.F., ANDRADE, G.P., CARVALHO, M.G., PIO-RIBEIRO, G. \& ZERBINI, F.M. Análise filogenética de potyvírus causando endurecimento dos frutos do maracujazeiro no Nordeste do Brasil. Fitopatologia Brasileira 29:378383. 2004.

\begin{abstract}
RESUMO
Amostras foliares de plantas de maracujá-amarelo (Passiflora edulis f. flavicarpa) com sintomas típicos de endurecimento dos frutos foram coletadas nos estados de Pernambuco, Paraíba e Sergipe. A infecção viral foi comprovada por meio de teste sorológico e gama de hospedeiros. Os seis isolados virais obtidos foram capazes de infetar várias espécies testadas, porém apresentando diferenças na intensidade dos sintomas induzidos nessas hospedeiras. Teste de ELISA indireto demonstrou que os isolados obtidos a partir de plantas de maracujá são sorologicamente relacionados entre si e com o potyvírus Cowpea aphid-borne mosaic virus (CABMV). A seqüência de aminoácidos da proteína capsidial foi determinada

para os seis isolados. A comparação dessas seqüências com as de outros potyvírus indicou uma identidade máxima com isolados de CABMV (86 a 94\%). A identidade com isolados de Passionfruit woodiness virus (PWV) foi de 68 a $76 \%$. Análise filogenética realizada a partir das seqüências de aminoácidos agrupou os isolados em estudo junto a isolados de CABMV, distante de isolados de PWV. Em conjunto, os resultados indicam que os isolados de maracujá analisados constituem na verdade uma estirpe do CABMV.

Palavras-chave adicionais: c aracterização molecular, proteína capsidial, maracujá, Passiflora edulis f. flavicarpa, $\mathrm{PWV}$, CABMV.
\end{abstract}

\section{ABSTRACT}

Phylogenetic analysis of potyvirus isolates causing passionfruit woodiness in Brazil

Leaf samples of yellow passionfruit plants (Passiflora edulis f. flavicarpa) showing woodiness symptoms in the fruit were collected in fields located in the states of Pernambuco, Paraíba and Sergipe. Virus infection was confirmed by serology and inoculation of indicator plants. The six viral isolates obtained from passionfruit were capable of infecting several plant species, although a difference in the intensity of symptoms induced by each isolate was observed in some hosts. Indirect ELISA showed that the passionfruit isolates were serologically related to each other, and also to the potyvirus Cowpea aphid-borne mosaic virus (CABMV). The amino acid sequence of the capsid protein was determined for the six isolates. Sequence comparisons with other potyviruses indicated a maximum degree of identity with CABMV (86 to 94\%). Sequence identity with isolates of Passionfruit woodiness virus (PWV) ranged from 68 to $76 \%$. Phylogenetic analysis based on the amino acid sequences confirmed that the Brazilian passionfruit isolates are closely related to CABMV, and only distantly related to PWV. Together, these results indicate that the potyvirus isolates obtained from passionfruit comprise a strain of CABMV.

\section{INTRODUÇÃO}

O endurecimento dos frutos é uma das doenças mais importante da cultura do maracujazeiro (Passiflora spp.) (Kitajima et al., 1986; Rezende, 1994). Plantas infetadas apresentam mosaico e frutos com endurecimento do pericarpo e grande redução da polpa (Kitajima et al., 1986). O Passionfruit woodiness virus (PWV) família Potyviridae, gênero Potyvirus foi descrito como agente causador do endurecimento dos frutos por Cobb, na Austrália, em 1901 (citado por Shukla \& Ward, 1988). Shukla \& Ward (1988)

\footnotetext{
* Parte da Dissertação de Mestrado do primeiro autor. Universidade Federal Rural de Pernambuco (2002)

** Bolsista CAPES; \# Bolsista CNPq
}

determinaram a seqüência de aminoácidos da proteína capsidial (CP) de três isolados de PWV provenientes da Austrália. Posteriormente, McKern et al. (1994) demonstraram que um isolado da África do Sul previamente classificado como PWV consistia na verdade em um vírus distinto, denominado South African Passiflora virus (SAPV). Estudos adicionais identificaram o SAPV como uma estirpe do Cowpea aphid-borne mosaic virus (CABMV) (Sithole-Niang et al., 1996). Dessa forma, reconhece-se atualmente que o endurecimento dos frutos do maracujazeiro pode ser causado pelo PWV ou pelo CABMV (Van Regenmortel et al., 2000). Ambos os vírus pertencem ao gênero Potyvirus da família Potyviridae. Os potyvírus possuem partícula alongada e flexuosa, com 690-760 nm de comprimento por 11-16 nm de 
Análise filogenética de potyvirus causando endurecimento dos frutos do...

largura. O genoma é constituído por um RNA de fita simples, sentido positivo, com aproximadamente 10.000 nucleotídeos (Van Regenmortel et al., 2000).

No Brasil, o endurecimento dos frutos já foi relatado nos principais estados produtores de maracujá, incluindo Bahia (Chagas et al., 1981), Ceará (Lima et al., 1985; Bezerra et al., 1995), Minas Gerais (Costa, 1996) e São Paulo (Chagas et al., 1992). Em todos os casos o PWV foi identificado como agente etiológico da doença, com base em características biológicas e sorológicas. Entretanto, estudos realizados por Braz et al. (1998) e Santana et al. (1999), baseados em análise comparativa da seqüência de aminoácidos da CP de diversos isolados brasileiros de potyvírus causadores de endurecimento dos frutos do maracujazeiro, previamente identificados como PWV, apontaram alta identidade das seqüências desses isolados com isolados de CABMV, e baixa identidade com isolados de PWV.

O presente trabalho teve por objetivo identificar e caracterizar isolados de potyvírus induzindo endurecimento dos frutos em maracujazeiro, coletados em áreas produtoras no Nordeste brasileiro.

\section{MATERIAL E MÉTODOS}

\section{Obtenção e manutenção dos isolados virais}

Plantas de maracujá-amarelo (Passiflora edulis d. flavicarpa Deg) apresentando frutos com endurecimento do pericarpo foram identificadas em plantios comerciais da cultura nos estados de Pernambuco (municípios de Bom Conselho e Petrolina), Paraíba (municípios de Conde e Alhandra) e Sergipe (município de Neopólis). A partir dessas plantas, coletaram-se folhas com sintomas de mosaico e deformação foliar. As folhas foram utilizadas para inoculação de plantas de feijoeiro (Phaseolus vulgaris L.) cv. Preto 153 e caupi [Vigna unguiculata (L.) subsp. unguiculata Walp.] cv. Pitiúba, via extrato vegetal tamponado em fosfato de potássio $0,05 \mathrm{M}, \mathrm{pH} 7,2$, contendo sulfito de sódio a $0,1 \%(\mathrm{p} / \mathrm{v})$. Os isolados virais obtidos dessa forma (Tabela 1) foram mantidos em plantas de maracujá-amarelo, caupi e Nicotiana benthamiana Domin., por meio de inoculações sucessivas via extrato vegetal tamponado. Os isolados foram também armazenados a $-20^{\circ} \mathrm{C}$ sob a forma de material foliar dessecado.

Além dos isolados obtidos de plantas de maracujáamarelo, um isolado brasileiro de CABMV obtido de plantas de amendoim (Arachis hypogaea L.) (CABMV-Br) (PioRibeiro et al., 2000) também foi utilizado nos experimentos subseqüentes, como controle.

\section{Caracterização biológica e sorológica}

A gama de hospedeiros parcial dos isolados foi determinada por meio de inoculações em Chenopodium amaranticolor Coste \& Reyn, C. quinoa Willd., C. murale L., Nicotiana clevelandii Gray, N. benthamiana, feijoeiro cvs. IPA 7419 e Preto 153 e caupi cvs. Pitiúba e Clay. As plantas foram inoculadas via extrato vegetal tamponado conforme descrito, realizando-se duas inoculações sucessivas em intervalo de três dias. Para cada isolado foram inoculadas três plantas de cada espécie. Como controle, uma planta de cada espécie foi tratada apenas com solução tampão. Os resultados foram avaliados por meio de observações periódicas de sintomas locais e sistêmicos durante um período de 30 dias a partir da primeira inoculação.

Para caracterização sorológica empregou-se a técnica de ELISA indireto, conduzida de acordo com o protocolo de Almeida (2001) e utilizando anti-soros policlonais contra PWV (cedido pelo Dr. E.W. Kitajima, ESALQ-USP, Piracicaba, SP), CABMV (cedido pelo Dr. J. Albérsio de A. Lima, Universidade Federal do Ceará, Fortaleza, CE) e Cucumber mosaic virus (CMV) família Bromoviridae, gênero Cucumovirus (cedido pelo Dr. J.W. Demski, University of Georgia, Griffin, Georgia, EUA). O ELISA indireto foi empregado para identificação de vírus nas amostras coletadas no campo, e para detecção viral nas plantas do experimento de gama de hospedeiros.

\section{Seqüênciamento do gene da proteína capsidial (CP)}

Folhas de $N$. benthamiana apresentando infecção sistêmica foram coletadas e utilizadas para a obtenção de uma preparação viral concentrada, utilizando o método descrito por Lane (1992). O RNA viral foi extraído a partir da preparação concentrada, conforme descrito por Krause-Sakate et al. (2001). O RNA viral foi empregado como molde para a síntese de cDNA via transcrição reversa, utilizando-se o kit "SuperScript Preamplification System for First Strand cDNA Synthesis" (GibcoBRL) e um oligonucleotídeo com uma seqüência de bases timina (poli-T: 5'G-A-C-T-G-G-A-T-C-C $\mathrm{T}_{(14)} 3^{\prime}$ ), conforme as instruções do fabricante. Para a amplificação da região codificadora da $\mathrm{CP}$ via reação em cadeia da polimerase (PCR), o oligonucleotídeo poli-T foi utilizado em conjunto com um oligonucleotídeo específico, desenhado a partir da seqüência da região codificadora da CP de um isolado de potyvírus causador de endurecimento dos frutos do maracujazeiro de Minas Gerais (poty-5: 5'G-C-GG-G-A-T-C-C-A-T-G-T-C-T-G-A-T-G-G-A-A-A-G-G-A-CA-A-A-G-A3') (Braz, 1999). As reações de PCR foram realizadas conforme descrito por Krause-Sakate et al. (2001). Os produtos de RT-PCR foram clonados utilizando-se o kit "pGEM-T-Easy Vector System" (Promega), conforme as instruções do fabricante. Os plasmídeos foram transferidos para Escherichia coli estirpe DH5 $\alpha$ utilizando-se o método do choque térmico (Sambrook et al., 1989) e os clones contendo plasmídeos recombinantes foram selecionados por meio de incubação em meio LB com ampicilina, IPTG e XGal, a $37^{\circ} \mathrm{C}$ por $12 \mathrm{~h}$. O DNA plasmidial desses clones foi isolado utilizando-se o método da lise alcalina (Sambrook et $a l ., 1989)$ e clivado com a enzima EcoR I para confirmação da presença do fragmento viral. Os fragmentos clonados foram seqüenciados pelo método de dideoxinucleotídeos terminadores utilizando-se o kit "BigDye Terminator Cycle Sequencing Ready Reaction” (Perkin Elmer), conforme as instruções do fabricante. As seqüências foram analisadas em um sequenciador automático ABI 310 (Applied Biosystems). A seqüência de aminoácidos da CP foi deduzida a partir da 
seqüência de nucleotídeos, para cada clone.

\section{Análise filogenética}

As seqüências de aminoácidos foram comparadas com seqüências de potyvírus relacionados disponíveis no GenBank (www.ncbi.nlm.nih.gov/Genbank) (Tabela 1). Alinhamentos múltiplos foram obtidos utilizando-se o programa Clustal W (www.ebi.ac.uk/Clustalw). A partir dos alinhamentos foram preparadas árvores filogenéticas utilizando-se o programa MEGA (www.megasoftware.net), utilizando-se o método de neighbour-joining com correção Poisson. Os ramos das árvores foram testados por bootstrap, com 2.000 repetições.

\section{RESULTADOS}

\section{Caracterização biológica e sorológica}

Os isolados virais obtidos de maracujazeiro causaram infecção sistêmica em $N$. benthamiana, $N$. clevelandii, feijoeiro cv. Preto 153 e caupi cvs. Pitiúba e Clay, e apenas infecção local em $C$. amaranticolor e C. quinoa. Não foi observada infecção local ou sistêmica em $C$. murale. As cultivares de caupi desenvolveram sintomas suaves de mosaico após inoculação com os isolados PB-1, PB-2, PE-3 e PE-4, e sintomas severos de mosaico após inoculação com os isolados PE-2 e SE-1. Em contrapartida, a cultivar de feijoeiro Preto 153 apresentou mosaico suave após inoculação com os seis isolados, enquanto a cultivar IPA 7419 não foi infetada por nenhum dos isolados. O isolado controle CABMV-Br infetou sistemicamente a cultivar de feijoeiro Preto 153 e ambas as cultivares de caupi. Entretanto, esse isolado não foi capaz de infetar maracujá-amarelo. Os resultados de ELISA indireto indicaram a existência de relacionamento sorológico entre os vírus isolados de maracujazeiro com PWV e CABMV, mas não com o CMV (Tabela 2).

\section{Determinação das seqüências de aminoácidos da CP e análise filogenética}

O padrão eletroforético da proteína capsidial e dos RNAs extraídos a partir de preparações concentradas confirmaram a infecção por potyvírus e a ausência de infecções mistas em todas as amostras testadas (dados não mostrados).

Nas amplificações via RT-PCR utilizando-se o par de oligonucleotídeos poty-5/poli-T, verificou-se a presença de um fragmento com aproximadamente 1.300 pares de bases (dados não mostrados). A partir do fragmento amplificado obteve-se a seqüência completa da região codificadora da $\mathrm{CP}$ para os seis isolados.

As seqüências de aminoácidos das CPs dos seis isolados possuem, todas, 275 resíduos. Essas seqüências quando comparadas entre si apresentam identidades de 92 a $98 \%$. Quando comparadas com as seqüências das CPs de outros potyvírus, a identidade máxima ( 86 a 94\%) é verificada com isolados de CABMV. A identidade com isolados do PWV varia de 68 a $76 \%$ (Tabela 3 ).

De acordo com a árvore filogenética preparada a partir das seqüências de aminoácidos da CP (Figura 1). Todos os isolados obtidos a partir de maracujá-amarelo se agruparam no mesmo ramo dos isolados de CABMV, ficando mais próximos dos isolados CABMV-Br (obtido de planta de amendoim no estado da Paraíba) e CABMV-SAP (obtido de planta de maracujá-amarelo na África do Sul). Os demais isolados, incluindo as estirpes de PWV, foram agrupados em ramos distintos da árvore.

TABELA 1 - Isolados virais e seqüências de aminoácidos utilizados neste estudo

A. Isolados de potyvírus obtidos a partir de plantas de maracujáamarelo (Passiflora edulis f. flavicarpa)

\begin{tabular}{llll}
\hline \hline Isolado & Hospedeiro & Origem & $\begin{array}{c}\text { Número de } \\
\text { acesso no } \\
\text { GenBank }\end{array}$ \\
\hline PB-1 & Maracujazeiro & Alhandra, PB & AY253907 \\
PB-2 & Maracujazeiro & Conde, PB & AY253910 \\
PE-2 & Maracujazeiro & Petrolina, PE & AY253906 \\
PE-3 & Maracujazeiro & Bom Conselho, PE & AY253908 \\
PE-4 & Maracujazeiro & Bom Conselho, PE & AY253909 \\
SE-1 & Maracujazeiro & Neopólis, SE & AY253911 \\
\hline
\end{tabular}

B. Seqüências de aminoácidos obtidas no GenBank

\begin{tabular}{|c|c|c|c|c|}
\hline Espécie ${ }^{a}$ & Estirpe & Hospedeiro & Origem & $\begin{array}{l}\text { Número de } \\
\text { acesso no } \\
\text { GenBank }\end{array}$ \\
\hline CABMV & $\mathrm{Br}$ & Amendoim & Brasil & AF241233 \\
\hline CABMV & SAP & Maracujazeiro & África do Sul & D10053 \\
\hline CABMV & $\mathrm{Ib}$ & Caupi & Costa do Marfim & AJ132414 \\
\hline CABMV & Mor & Caupi & Marrocos & Y18634 \\
\hline CABMV & Mon & Caupi & Zimbábue & Y17822 \\
\hline PWV & $\mathrm{K}$ & Maracujazeiro & Austrália & $1906186 \mathrm{~A}$ \\
\hline PWV & M & Maracujazeiro & Austrália & P32574 \\
\hline PWV & $\mathrm{S}$ & Maracujazeiro & Austrália & P32575 \\
\hline BCMV & NL1 & Feijoeiro & EUA & L15332 \\
\hline BCMV & NL2 & Feijoeiro & EUA & L19472 \\
\hline BCMNV & NL3 & Feijoeiro & EUA & U19287 \\
\hline BCMV & NL4 & Feijoeiro & EUA & L21766 \\
\hline PStV & & Amendoim & EUA & U05771 \\
\hline SPFMV & $\mathrm{S}$ & $\begin{array}{l}\text { Batata-doce } \\
\text { Ipomoea batato } \\
\text { (L.) Lam }\end{array}$ & $\begin{array}{l}\text { EUA } \\
\text { as }\end{array}$ & NP045216 \\
\hline
\end{tabular}

${ }^{\mathrm{a} C A B M V}$, Cowpea aphid-borne mosaic virus; BCMV, Bean common mosaic virus; BCMNV, Bean common mosaic necrosis virus; PStV, Peanut stripe virus; PWV, Passionfruit woodiness virus; SPFMV, Sweet potato feathery mottle virus.

TABELA 2 - Valores médios de absorbância a $405 \mathrm{~nm}$ obtidos em ELISA indireto para identificação dos vírus isolados de maracujazeiro (Passiflora spp.)

\begin{tabular}{lccccccc}
\hline \hline \multirow{2}{*}{ Anti-soro } & \multirow{2}{*}{ Sadia } & \multicolumn{6}{c}{ Isolados } \\
\cline { 3 - 8 } & & PE-2 & PB-1 & PE-3 & PE-4 & PB-2 & SE-1 \\
\hline CABMV & 0,109 & 0,719 & 0,728 & 0,676 & 0,645 & 0,757 & 0,815 \\
PWV & 0,088 & 0,660 & 0,718 & 0,671 & 0,511 & 0,642 & 0,760 \\
CMV & 0,119 & 0,229 & 0,207 & 0,180 & 0,222 & 0,217 & 0,216 \\
\hline
\end{tabular}


Análise filogenética de potyvirus causando endurecimento dos frutos do...

\section{DISCUSSÃO}

Até o início da década de 1990, acreditava-se que a única espécie de potyvírus causadora de endurecimento dos frutos em maracujazeiro era o PWV. Entretanto, estudos recentes demonstraram que na África do Sul a doença é causada por uma estirpe do CABMV (McKern et al., 1994; Sithole-Niang et al., 1996). Estirpes "típicas" do CABMV infetam caupi, feijoeiro comum e outras espécies de leguminosas, mas não infetam o maracujazeiro (Pio-Ribeiro et al., 2000). No Brasil, historicamente, isolados virais causando endurecimento dos frutos em maracujazeiro têm sido identificados com base em características biológicas e sorológicas (Inoue et al., 1995; Costa, 1996).

Os resultados do teste de gama de hospedeiros e ELISA indireto confirmaram a infecção das plantas coletadas no campo por potyvírus. Todos os seis isolados analisados causaram infecção sistêmica em duas cultivares de caupi (Pitiúba e Clay), embora tenham sido observadas variações na severidade dos sintomas induzidos nessas cultivares pelos diferentes isolados: os isolados PE-2 e SE-1 induziram sintomas mais severos em relação aos demais isolados. Este resultado difere daqueles obtidos por Inoue et al. (1995) e Costa (1996), que relataram ausência de sintomas em caupi após inoculação com isolados de potyvírus causadores de endurecimento dos frutos em maracujazeiro. É possível que os isolados estudados por esses autores sejam distintos dos

TABELA 3 - Porcentagem de identidade da seqüência de aminoácidos da proteína capsidial dos isolados brasileiros de potyvírus causadores de endurecimento dos frutos do maracujazeiro (Passiflora spp.) e de outros potyvírus relacionados

\begin{tabular}{lcccccc}
\hline \multirow{2}{*}{ Virus $^{\text {a }}$} & \multicolumn{6}{c}{ Isolados de PWV obtidos de maracujazeiro } \\
\cline { 2 - 7 } & PE-2 & PB-1 & PE-3 & PE-4 & PB-2 & SE-1 \\
\hline PE-2 & - & - & - & - & - & - \\
PB-1 & 94 & - & - & - & - & - \\
PE-3 & 94 & 92 & - & - & - & - \\
PE-4 & 94 & 92 & 98 & - & - & - \\
PB-2 & 94 & 98 & 92 & 92 & - & - \\
SE-1 & 93 & 93 & 92 & 92 & 92 & - \\
CABMV-Br & 91 & 92 & 90 & 90 & 92 & 94 \\
CABMV-SAP & 89 & 89 & 86 & 86 & 88 & 88 \\
CABMV-Ib & 88 & 88 & 86 & 86 & 88 & 88 \\
CABMV-Mor & 87 & 87 & 86 & 86 & 87 & 89 \\
CABMV-Mon & 87 & 88 & 86 & 86 & 88 & 87 \\
PWV-K & 74 & 76 & 72 & 72 & 69 & 70 \\
PWV-M & 75 & 73 & 71 & 71 & 68 & 68 \\
PWV-S & 75 & 73 & 72 & 72 & 75 & 75 \\
BCMV-NL1 & 65 & 70 & 65 & 65 & 70 & 77 \\
BCMV-NL2 & 73 & 78 & 73 & 73 & 78 & 71 \\
BCMNV-NL3 & 72 & 79 & 72 & 72 & 79 & 76 \\
BCMV-NL4 & 66 & 70 & 66 & 66 & 7 & 71 \\
PStV & 78 & 78 & 73 & 73 & 78 & 78 \\
SPFMV-S & 54 & 60 & 54 & 54 & 56 & 59 \\
\hline
\end{tabular}

${ }^{\mathrm{a}} \mathrm{CABMV}$, Cowpea aphid-borne mosaic virus; $\mathrm{BCMV}$, Bean common mosaic virus; BCMNV, Bean common mosaic necrosis virus; PStV, Peanut stripe virus; PWV, Passionfruit woodiness virus; SPFMV, Sweet potato feathery mottle virus. coletados durante este trabalho, apresentando diferenças em suas gamas de hospedeiros. É possível também que certas cultivares de caupi sejam resistentes ao vírus. A variação na resposta de diferentes cultivares de caupi à infecção pelo vírus é sugerida pelas diferenças na severidade dos sintomas induzidos pelos isolados PE-2 e SE-1 nas duas cultivares analisadas.

Embora a sorologia tenha sido empregada diversas vezes para a identificação de isolados brasileiros de "PWV" (Inoue et al., 1995; Bezerra et al., 1995), não existem relatos de relacionamento sorológico entre isolados brasileiros e isolados de PWV provenientes da Austrália, único país onde até então haviam sido obtidas seqüências da proteína capsidial de isolados de PWV (Shukla \& Ward, 1988). Entretanto, relacionamento sorológico foi observado por Bezerra et al. (1995) entre um isolado brasileiro classificado como PWV e o CABMV, Clitoria mosaic virus (ClMV) e Sirato mosaic virus (SrMV). Neste trabalho, todos os seis isolados apresentaram reação positiva em teste de ELISA indireto utilizando um anti-soro policlonal produzido a partir de um isolado de potyvírus causador de endurecimento dos frutos coletado no

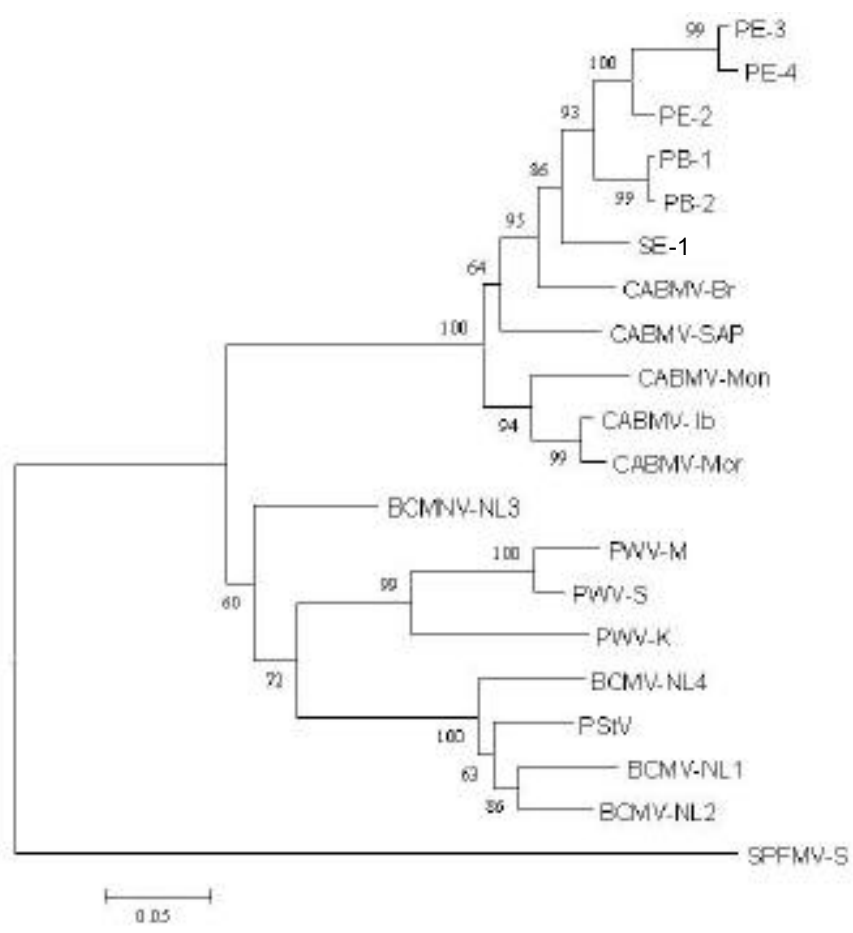

FIG. 1 - Árvore filogenética preparada a partir das seqüências de aminoácidos da proteína capsidial de isolados de potyvírus causadores de endurecimento dos frutos do maracujazeiro (Passiflora spp.), e de alguns potyvírus relacionados. O comprimento dos ramos horizontais é proporcional à distância genética entre os isolados; os ramos verticais são arbitrários. Os números sobre os ramos indicam a porcentagem de repetições da análise de bootstrap na qual as ramificações foram observadas. CABMV, Cowpea aphid-borne mosaic virus; $\mathrm{BCMV}$, Bean common mosaic virus; $\mathrm{BCNMV}$, Bean common mosaic necrosis virus; PStV, Peanut stripe virus; PWV, Passionfruit woodiness virus; SPFMV, Sweet potato feathery mottle virus. 
Distrito Federal, e classificado como PWV (Inoue et al., 1995). Todos os isolados reagiram também contra um anti-soro produzido a partir de um isolado brasileiro de CABMV (CABMVBr, Pio-Ribeiro et al., 2000). Esse resultado comprova a existência de relacionamento sorológico entre os seis isolados aqui analisados e o CABMV. Além disso, indiretamente, esse resultado indica que o isolado do Distrito Federal classificado como PWV também apresenta relacionamento sorológico com o CABMV. O relacionamento sorológico entre potyvírus é complexo e muitas vezes inconsistente. Variabilidade de reações cruzadas entre anti-soros policlonais, relacionamentos inesperados entre vírus distintos e ausência de reações cruzadas entre algumas estirpes da mesma espécie são os principais problemas associados com a sorologia dos potyvírus (Ellis et al., 1997). Os resultados obtidos por diferentes autores, bem como os resultados obtidos neste trabalho, sugerem a existência de relacionamento sorológico entre o PWV e o CABMV, tornando a sorologia uma técnica pouco recomendável para a caracterização de isolados de potyvírus causadores de endurecimento dos frutos em maracujazeiro.

A caracterização molecular comprovou a identidade dos seis isolados analisados como estirpes do CABMV. As seqüências de aminoácidos da CP de todos os isolados apresentaram uma identidade de 86 e $94 \%$ com isolados dessa espécie. É interessante ressaltar que, dentre as cinco seqüências de isolados de CABMV utilizadas nas comparações, aquela que apresentou a maior identidade com os isolados brasileiros foi a do isolado CABMV-Br (90 a 94\%). Esse isolado pertence à estirpe "típica" do CABMV, foi obtido no Brasil (estado da Paraíba) a partir de planta de amendoim e não infeta o maracujazeiro. As outras quatro sequências são de isolados de CABMV provenientes da África. Um deles, CABMV-SAP, foi obtido a partir de plantas de maracujazeiro, enquanto os demais foram obtidos de caupi. Esses quatro isolados apresentaram identidades semelhantes com os isolados brasileiros, variando de 86 a $89 \%$. Observa-se dessa forma uma correlação entre o nível de identidade da seqüência da $\mathrm{CP}$ dos isolados e sua origem geográfica. Inversamente, não é observada correlação entre a identidade da seqüência da CP e a capacidade dos isolados de infetarem o maracujazeiro. Observe-se que os isolados PB-1 e PB-2, ambos provenientes do estado da Paraíba, se agruparam no mesmo ramo na árvore filogenética. O mesmo foi observado para os dois isolados de Pernambuco (PE-3 e PE-4). Esses resultados reforçam a correlação entre o grau de identidade da seqüência da CP dos isolados e sua origem geográfica.

Estudos realizados por Braz et al. (1998) e Santana et al. (1999) constataram que diversos isolados de potyvírus causadores do endurecimento dos frutos do maracujazeiro, provenientes dos principais estados produtores de maracujá no Brasil (São Paulo, Minas Gerais, Rio de Janeiro, Espírito Santo, Bahia, Pernambuco e Pará, além do Distrito Federal) e previamente classificados como PWV com base em características biológicas e sorológicas, também constituem uma estirpe do CABMV. Dessa forma, o CABMV pode ser considerado como a principal espécie de potyvírus causadora de endurecimento dos frutos do maracujazeiro no Brasil. Essa informação é de grande relevância para a busca de estirpes atenuadas do vírus para proteção cruzada, e em programas de melhoramento genético visando a resistência ao endurecimento dos frutos. Estudos adicionais serão necessários, analisandose um número maior de amostras de plantas de maracujazeiro com sintomas de endurecimento dos frutos, a fim de confirmar a ocorrência do PWV no Brasil.

\section{AGRADECIMENTOS}

Os autores agradecem o apoio financeiro da FAPEMIG (CAG 813/99), e aos colegas do laboratório de Virologia Vegetal Molecular (UFV-BIOAGRO) e de Fitovirologia (UFRPE).

\section{REFERÊNCIAS BIBLIOGRÁFICAS}

ALMEIDA, A.M.R. Detecção e quantificação de vírus pelo teste de ELISA. In: Almeida, A.M.R. \& Lima, J.A.A. (Eds.). Princípios e técnicas de diagnose aplicados em fitovirologia. Brasília: Sociedade Brasileira de Fitopatologia. 2001. pp.63-94.

BEZERRA, D.R., LIMA, J.A.A. \& XAVIER FILHO, J. Purificação e caracterização de um isolado cearense do vírus do endurecimento dos frutos do maracujazeiro. Fitopatologia Brasileira 20:553560.1995

BRAZ, A.S.K. Clonagem e seqüenciamento dos genes da proteína capsidial e da replicase de um Potyvirus causador de endurecimento dos frutos do maracujazeiro, e transformação de maracujá-amarelo com construção derivada desses genes. Tese M.S., Dep. de Fitopatologia, Universidade Federal de Viçosa, Viçosa, MG. 1999.

BRAZ, A.S.K., SANTANA, E.N., ZAMBOLIM, E.M., COSTA, A.F., OTONI, W.C. \& ZERBINI, F.M. Molecular characterization of two isolates of South African Passiflora virus infecting passionfruit in Brazil. Virus Reviews and Research 3:146. 1998. (Abstract).

CHAGAS, C.M., KITAJIMA, E.W. \& LIN, M.T. Grave moléstia em maracujá amarelo (Passiflora edulis f. flavicarpa) no Estado da Bahia causada por um isolado do vírus do "woodiness" do maracujá. Fitopatologia Brasileira 6:259-268. 1981.

CHAGAS, C.M., REZENDE, J.A.M., COLARICCIO, A., PIZA Jr., C.T., LOPES, L.C., FERRARI, J.T. \& BELLUZI, B.M. Ocorrência do endurecimento do fruto do maracujazeiro no Estado de São Paulo. Revista Brasileira de Fruticultura 14:187-190. 1992.

COSTA, A.F. Comportamento de Passiflora spp. diante do vírus do endurecimento dos frutos do maracujazeiro e a relação entre a nutrição mineral e a interação vírus-Passiflora edulis f. flavicarpa. Tese D.S., Dep. de Fitopatologia, Universidade Federal de Viçosa, MG. 1996.

ELLIS, P., STACE-SMITH, R. \& De VILLIERS, G. Identification and geographic distribuition of serotypes of potato virus Y. Plant Disease 81:481-484. 1997.

INOUE, A.K., MELLO, R.N., NAGATA, T. \& KITAJIMA, E.W. Characterization of Passionfruit woodiness virus isolates from Brasília and surrounding region, Brazil. Fitopatologia Brasileira 20:479-485. 1995.

KITAJIMA, E.W., CHAGAS, C.M. \& CRESTANI, O.A. Enfermidades de etiologia viral e associadas a organismos do tipo 
Análise filogenética de potyvirus causando endurecimento dos frutos do...

micoplasma em maracujazeiro no Brasil. Fitopatologia Brasileira 11:409-432. 1986.

KRAUSE-SAKATE, R., MELLO, R.N., PAVAN, M.A., ZAMBOLIM, E.M., CARVALHO, M.G., LEGALL, O. \& ZERBINI, F.M. Molecular characterization of two Brasilian isolates of Lettuce mosaic virus with distinct biological properties. Fitopatologia Brasileira 26:153-157. 2001.

LANE, L.C. A general method for detecting plant viruses. In: Maramorosch, K. (Ed.) Plant diseases of viral, viroid, mycoplasma and uncertain origin. New Delhi, India: Oxford and IBH Publishing. 1992. pp.3-17

LIMA, J.A.A., SANTOS, C.D.G. \& KITAJIMA, E.W. Isolamento de um potyvírus de plantas de maracujá com sintomas de mosaico. Fitopatologia Brasileira 10: 305. 1985 (Resumo).

McKERN, N.M., STRIKE, P.M., BARNETT, O.W., DIJKSTRA, J., SHUKLA, D.D.\& WARD, C.W. Cowpea aphid-borne mosaic virusMorocco and South African Passiflora virus are strains of the same potyvirus. Archives of Virology 136:207-217. 1994.

PIO-RIBEIRO, G., PAPPU, S.S., PAPPU, H.R., ANDRADE, G.P. \& REDDY, D.V.R. Occurrence of Cowpea aphid-borne mosaic virus in peanut in Brazil. Plant Disease 84:760-766. 2000.

REZENDE, J.A.M. Doenças de vírus e micoplasma do maracujazeiro no Brasil. In: São José, A.R. (Ed.) Maracujá: produção e mercado. Vitória da Conquista: UESB 1994. pp.116-125.

SAMBROOK, J., FRITSCH, E.F. \& MANIATIS, T. Molecular Cloning - A Laboratory Manual (2 $2^{\text {a }}$ ed.). Cold Spring Harbor, NY: Cold Spring Harbor Laboratory Press. 1989.

SANTANA, E.N., BRAZ, A.S.K., TORRES, L.B., ZAMBOLIM, E.M. \& ZERBINI, F.M. Molecular characterization of Potyvirus isolates causing passionfruit woodiness in Brazil. Virus Reviews and Research 4(Supplement):153. 1999 (Abstract).

SHUKLA, D.D. \& WARD, C.W. Amino acid sequence homology of coat protein as a basis for identification and classification of the potyvirus group. Journal of General Virology 69:2703-2710. 1988.

SITHOLE-NIANG, I., NYATHI, T., MAXWELL, D.P. \& CANDRESSE, T. Sequence of the 3'-terminal of a Zimbabwe isolate of Cowpea aphid-borne mosaic virus (CABMV). Archives of Virology 141:935-943. 1996.

VAN REGENMORTEL, M.H.V., FAUQUET, C.M., BISHOP, D.H.L., CARSTENS, E., ESTES, M.K., LEMON, S., MANILOFF, J., MAYO, J.A., McGEOCH, D.J., PRINGLE, C.R. \& WICKNER, R. (Eds.) Virus taxonomy. Classification and nomenclature of viruses. Seventh report of the International Committee on the Taxonomy of Viruses. New York: Academic Press. 2000. 